\title{
A comparison of the keypeck and treadle-press operants in the pigeon: Fixed-interval schedule of reinforcement
}

\author{
W. KIRK RICHARDSON and NANCY RAINWATER \\ Georgia State University, Atlanta, Georgia 30303
}

\begin{abstract}
Four pigeons were tested under 30-, 100-, 600-, and 1,000-sec values of the fixed-interval schedule of food presentation using both the treadle-press and the keypeck operants. Response rate was higher for the keypeck response at all schedule values, but the response pattern was similar for both operants. Quantitative measures of response rate and curvature showed considerable variability, with indication of a differential change in quarter-life as a function of schedule value, with the function being steeper for the treadle response than for the key response. Overall, responding on the key and treadle showed more similarities than differences.
\end{abstract}

The activities of psychologists have, in recent years, been increasingly influenced by questions concerning the generality of behavioral laws constructed from data obtained using traditional experimental situations. Concurrently, the response system being studied and interactions between the response system and stimuli in the test environment came to be considered important independent variables that partially controlled behavior. Seligman (1970) proposed that evolutionary processes have resulted in species differences in speed of acquisition of different responses and in the formation of associations between stimuli or between responses and stimuli. Data supporting this type of analysis include Bolles' (1970) observation that the single most effective variable in avoidance conditioning may be the response chosen for study. Also, the learned taste aversion literature shows that, with the appropriate combination of species, task, and stimuli, associations can be formed with very long delays between occurrences of the associated elements (Revusky \& Garcia, 1970). Such considerations indicate that the assumption that the study of a few response systems could allow discovery of general laws of behavior (Skinner, 1969, p. 108) must now be examined and clarified.

One procedure for the study of different response systems has involved comparison of keypecking and treadle pressing in the pigeon. These two responses of the pigeon seem quite different in terms of biological importance and selectivity in development from an evolutionary perspective. The highly visible

Portions of these data were presented at the 23rd Annual Meeting of the Southeastern Psychological Association, Hollywood Beach, 1977. We wish to thank S. Ward for assistance in data collection and the Computer Center of Georgia State University for providing the computer time and programs necessary to obtain and analyze the data. Reprints may be obtained from W. Kirk Richardson, Department of Psychology, Georgia State University, Atlanta, Georgia 30303. peck is frequently emitted by the pigeon, as it is involved in feeding, fighting, and other behaviors. Treadle responses, in comparison, seem not to have been left with any special characteristics by evolutionary processes. Several reports have shown that pigeons rapidly learn when treadle pressing is the avoidance response, while avoidance learning is slow or does not occur when the avoidance response is pecking (e.g., Klein \& Rilling, 1972). Multiple schedules that yielded positive behavioral contrast when keypecking was the response did not show positive behavioral contrast when treadle pressing was the response (Hemmes, 1973; Westbrook, 1973). Both behavioral contrast and matching have been observed when treadle pressing was reinforced according to a concurrent schedule (McSweeney, 1975). Richardson and Clark (1976), using a differentialreinforcement-of-low-rate schedule, found several measures of behavior to be similar for the treadle-press and keypeck responses when differences in response rate were ignored, although the peck response was more sensitive to temporal requirements, while the treadle response resulted in fewer responses per reinforcement. Thus, comparisons of keypecking and treadle pressing sometimes, but not always, indicate a response system difference. Unfortunately, no present analysis accurately predicts under what conditions response system effects will be observed.

At present, there is a need to obtain more data comparing response systems under controlled, standard laboratory conditions in order to lay a solid empirical foundation for a conceptual analysis of the response system variable. As schedules of reinforcement have been frequently studied, and as schedules are a powerful and pervasive determinant of behavior, it is important to determine if schedule variables interact with response systems. The present study compared keypecking and treadle pressing under four values of a fixed-interval (FI) schedule of food presentation. The 
FI schedule was chosen because it produces a characteristic and readily identifiable distribution of responses that varies with time from the beginning of the interval (Ferster \& Skinner, 1957), and because FI schedules have been studied with several species under many different conditions.

\section{METHOD}

\section{Subjects}

Four homing pigeons, approximately 28 months of age at the beginning of the experiment, were maintained at $70 \%$ of their free-feeding weights during preliminary training and at $75 \%$ during the experiment proper, except that $\mathrm{P} 1$ was returned to $70 \%$ during the first exposure to FI $100-\sec$ (treadle) and was maintained at this weight for the duration of the experiment. P1 and P2 were naive; P3 and P4 had a few sessions of keypeck training in which each response produced food prior to this study.

\section{Apparatus}

Birds were tested in four operant chambers with inside dimensions $50 \mathrm{~cm}$ long, $36 \mathrm{~cm}$ wide, and $35 \mathrm{~cm}$ high. Response panels in each chamber had a keyhole $2.5 \mathrm{~cm}$ in diameter centered $22 \mathrm{~cm}$ above the floor. The response key was a translucent Plexiglas paddle that could be transilluminated from the rear with white light. A force of $15-20 \mathrm{~g}(.15-.20 \mathrm{~N})$ with an excursion of $1 \mathrm{~mm}$ was required to operate the response key. During conditions in which the key was not used, the keyhole was covered by a metal plate the same color as the response panel. A wooden treadle, $5 \mathrm{~cm}$ wide and $6.5 \mathrm{~cm}$ long, extending from a box $15.5 \mathrm{~cm}$ long, $6 \mathrm{~cm}$ wide, and $8 \mathrm{~cm}$ high, was located in a corner of the chamber. The back of the treadle box was against the right side of the response panel, and the right side of the treadle box was against the adjacent wall. The treadle was $3 \mathrm{~cm}$ above the floor and approximately $25 \mathrm{~cm}$ from the opening of the food magazine. Two stimulus lamps were mounted near the front of the upper surface of the treadle box, and the entire treadle box was painted gray. The white stimulus lamp on the treadle box was used as an operandum

Table 1

Order and Duration of Experimental Conditions

\begin{tabular}{|c|c|c|c|c|c|c|c|c|}
\hline \multirow{2}{*}{$\begin{array}{c}\text { FI } \\
\text { (Seconds) }\end{array}$} & \multicolumn{2}{|c|}{ P1 } & \multicolumn{2}{|c|}{ P2 } & \multicolumn{2}{|c|}{ P3 } & \multicolumn{2}{|c|}{ P4 } \\
\hline & 0 & $S$ & 0 & $\mathrm{~S}$ & 0 & $S$ & 0 & $\mathbf{S}$ \\
\hline 30 & $\mathbf{T}$ & 24 & $\mathbf{T}$ & 24 & $\mathrm{~T}$ & 24 & $\mathrm{~T}$ & 24 \\
\hline 100 & $\mathrm{~T}$ & 24 & $T$ & 24 & $\mathrm{~T}$ & 24 & $T$ & 24 \\
\hline 600 & $\mathrm{~T}$ & 22 & $\mathbf{T}$ & 22 & $\mathrm{~T}$ & 22 & $\mathrm{~T}$ & 22 \\
\hline 1000 & $\mathrm{~T}$ & 28 & $\mathrm{~T}$ & 28 & $\mathrm{~T}$ & 32 & $\mathrm{~T}$ & 28 \\
\hline 1000 & K & 44 & K & 7 & $\mathbf{K}$ & 44 & $\mathbf{K}$ & 44 \\
\hline 1000 & $T$ & 16 & $T$ & 4 & $\mathrm{~T}$ & 16 & $\mathbf{T}$ & 16 \\
\hline 1000 & & & $\mathbf{K}$ & 34 & & & & \\
\hline 1000 & & & $\mathrm{~T}$ & 16 & & & & \\
\hline 600 & $\mathbf{K}$ & 36 & $\mathbf{K}$ & 36 & $\mathbf{K}$ & 36 & $\mathbf{K}$ & 36 \\
\hline 100 & $\mathbf{K}$ & 49 & $\mathbf{K}$ & 49 & $\mathbf{K}$ & 49 & $\mathbf{K}$ & 49 \\
\hline 30 & $\mathbf{K}$ & 28 & $\mathrm{~K}$ & 28 & $\mathbf{K}$ & 28 & $\mathbf{K}$ & 28 \\
\hline 600 & $\mathbf{K}$ & 22 & $\mathbf{K}$ & 22 & $T$ & 22 & $T$ & 22 \\
\hline 30 & $\mathbf{K}$ & 27 & $\mathrm{~K}$ & 38 & $\mathrm{~T}$ & 14 & $\mathbf{T}$ & 14 \\
\hline 30 & & & & & $\mathbf{K}$ & 27 & $\mathbf{K}$ & 20 \\
\hline 100 & $\mathrm{~T}$ & 20 & $\mathrm{~T}$ & 20 & $\mathbf{K}$ & 20 & $\mathbf{K}$ & 38 \\
\hline 100 & $\mathbf{K}$ & 32 & $\mathbf{K}$ & 15 & $\mathrm{~T}$ & 14 & $\mathrm{~T}$ & 14 \\
\hline 600 & $\mathbf{T}$ & 42 & $T$ & 11 & $\mathbf{T}$ & 2 & $\mathbf{K}$ & 42 \\
\hline 600 & & & & & $\mathbf{K}$ & 22 & & \\
\hline 600 & & & & & $\mathrm{~T}$ & 18 & & \\
\hline
\end{tabular}

Note $-O=$ operandum, $S=$ number of sessions; $T=$ treadle operandum, $K=$ key operandum. light. A force of $30-35 \mathrm{~g}(.30-.35 \mathrm{~N})$ with an excursion of $10 \mathrm{~mm}$ was required to operate the treadle. The treadle was removed from the chamber during conditions in which it was not used.

Food presentation was 3-sec access to pigeon chow delivered through an opening $5 \mathrm{~cm}$ high by $6 \mathrm{~cm}$ wide, located $14 \mathrm{~cm}$ below the key, and illuminated by a white light during feeder operations. Houselights consisted of two $28-\mathrm{V}$ bulbs behind a Plexiglas screen placed across the top of the response panel. An IBM 1800 data acquisition system located in an adjacent room controlled the experiment and recorded each interresponse time (IRT) having a duration greater than $50 \mathrm{msec}$.

\section{Procedure}

After four sessions of adaptation to the test chambers and four sessions of magazine training, treadle pressing was shaped by the method of successive approximations. Next the birds were trained under a $1-\sec$ schedule with a 5 -sec time-out (TO). During TO, houselights and operanda lights were extinguished, and responses were not counted. The FI value was gradually increased over 17 sessions until the birds were placed under FI 30 TO $15 \mathrm{sec}$. Subsequently, the birds were tested under $30-, 100-, 600-$, and 1,000-sec values of the FI schedule with the TO always being $15 \mathrm{sec}$. The birds were exposed to all four FI values with the treadle and were then alternated between key and treadle so that they were exposed to most conditions twice. Keypecking was shaped by the method of successive approximations during the first condition with the keypeck response. P3 and P4 already keypecked, due to their prior keypecking training. Conditions were changed when response rate showed no systematic change over five consecutive sessions. During the first three conditions, all birds' behavior was required to be stable before any conditions were changed. Later, conditions were sometimes changed on an individual basis. Table 1 gives the sequence of conditions and number of sessions under each condition. Each session lasted for 29 or 30 food presentations under FI values of 30 and $100 \mathrm{sec}$ and for 27 food presentations under FI values of 600 and $1,000 \mathrm{sec}$.

The first response after passage of a period of time equal to the FI value resulted in food presentation and concurrent initiation of the TO. The next interval was timed from the end of TO. At the beginning of a session, the birds were placed in dark chambers, lights came on about $10 \mathrm{~min}$ later, and the first interval began; all lights were extinguished at the end of the session.

\section{RESULTS AND DISCUSSION}

Replication data were not available for FI 1,000 sec due to technical difficulties. Bird P2 pecked the treadle during replication of the 100- and $600-\mathrm{sec}$ values, so these data are not presented. The other birds were seldom observed to peck the treadles. All measures were computed for each individual interval, and means were taken to obtain the data presented in the figures.

\section{Response Rates}

The response rates are plotted as a function of FI value in Figure 1. The left panel of Figure 1 presents total response rates, which were obtained by dividing the total number of responses emitted by the total amount of stimulus on time. In general, total response rate decreased as FI value increased for both key and treadle in each case. The highest treadle daily response rate was lower than the lowest key daily response rate for each bird at each FI value; that is, key and treadle distributions did not overlap. 


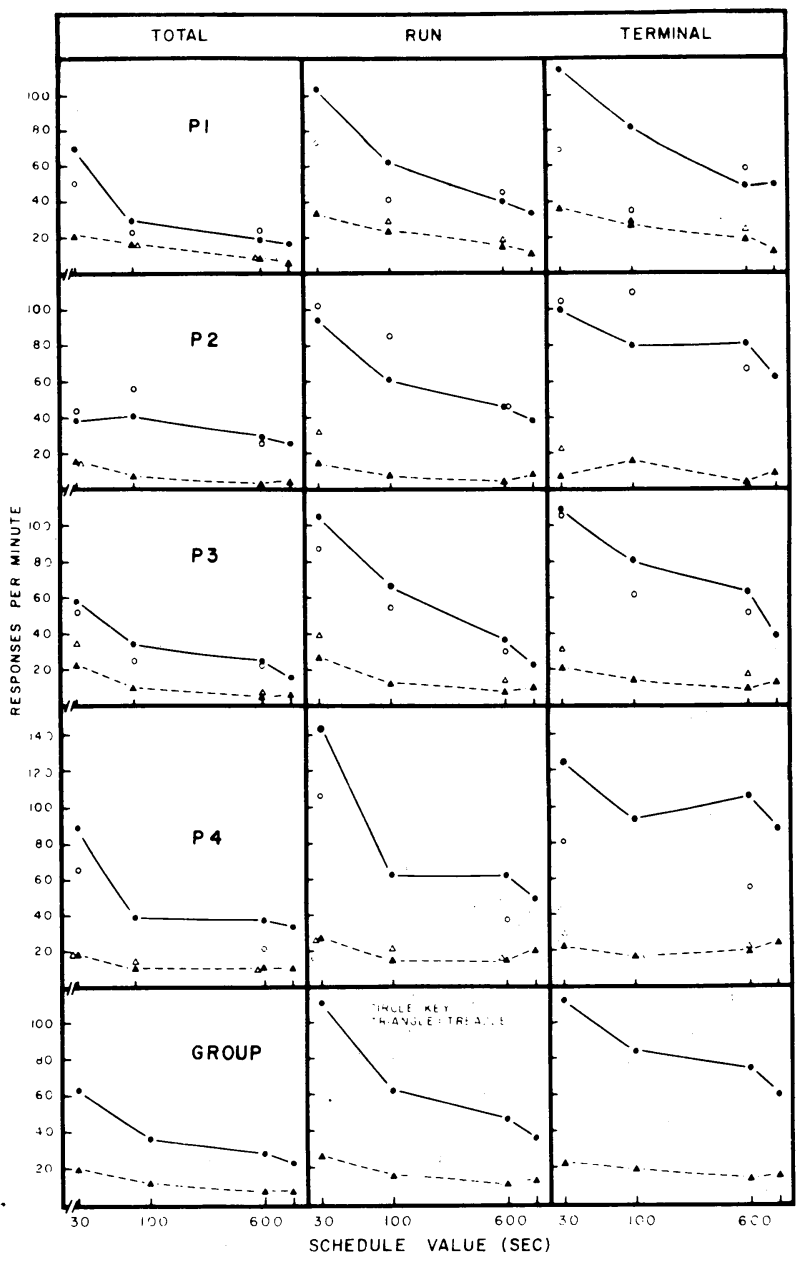

Figure 1. Mean total, run, and terminal response rates as a function of schedule value for the key (circles) and the treadle (triangles) operants with the schedule value plotted on a logarithmic scale. Each point is a mean over the last 20 intervals of the last four sessions in a condition. The first exposure to a condition is represented by solid symbols that are connected by lines. The second exposure to a condition is represented by open symbols. The group graphs are based on the first exposure to each condition only.

The middle panel of Figure 1 presents run rates, which were computed as the number of responses in an interval minus one divided by the total stimulus on time minus the FI pause. Run rate on the key was higher than run rate on the treadle, and both functions decreased as FI value increased. The highest daily run rate on the treadle was lower than the lowest daily run rate on the key for each bird at each FI value; that is, the key and treadle distributions did not overlap.

The right panel of Figure 1 presents terminal response rates (response rates in the last one-fifth of the interval). Again, terminal response rate for the key was greater than terminal response rate for the treadle, and the functions tended to decrease as FI value increased. The key and treadle daily terminal response rate distributions did not overlap except for P1 at FI $100 \mathrm{sec}$. The terminal rate functions showed an increase for the treadle response at FI 1,000 sec in three of the four birds.

\section{Measures of Curvature}

Absolute and relative FI pause (time from key light onset to the first response) and quarter-life (percent of the interval that passes before $25 \%$ of the total responses in that interval are emitted) are presented in Figure 2. Absolute FI pause increased as a function of FI value for both operanda. The relative FI pause functions showed considerable interbird variability. For example, both functions were relatively flat for P4, while for P3 the functions crossed, with an increasing relative FI pause for treadle pressing and a decreasing relative FI pause for keypecking. All birds showed a treadle FI pause equal to (one bird) or greater than (three birds) the key FI pause at 1,000 sec. The relative FI pause functions had overlap of key and treadle distributions at one to three schedule values for different birds.

Key quarter-life was fairly stable across FI values (70\%-75\%), with a slight tendency to increase. Treadle quarter-life was less than key quarter-life at the 100-sec value for all birds, increasing to approximately the same level as the key at higher schedule values. However, the second exposure yielded almost identical quarter-

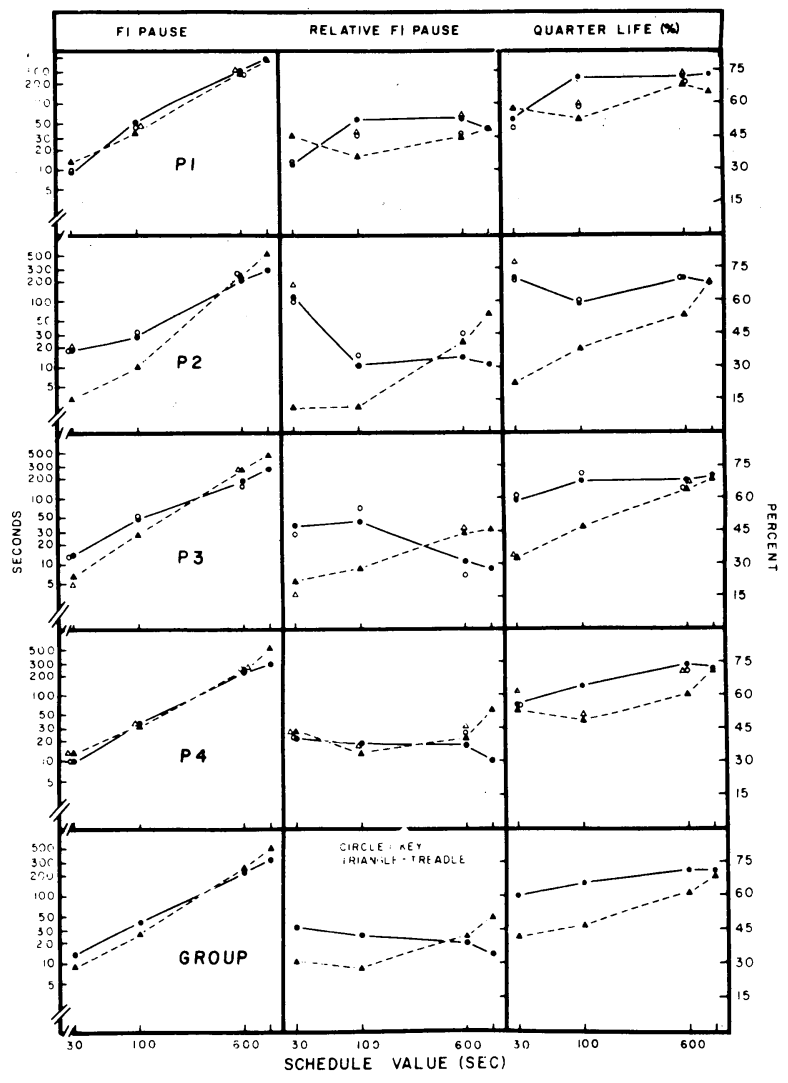

Figure 2. FI pause, relative FI pause (FI pause/schedule value), and quarter-life (percent of the interval necessary for $25 \%$ of the total interval responses to be emitted) as a function of FI value. Details are the same as those in Figure 1. 
lives for the two operanda at the 100-sec value for P1. Key and treadle daily quarter-lives had overlapping distributions at two or three schedule values for each bird.

When treadle pressing was maintained under the FI schedule, typical response patterns occurred. Response rate was zero or near zero at the beginning of the interval and increased to a high rate at the end of the interval. The number of responses per interval and the length of the FI pause varied greatly from interval to interval. At this level of analysis, only one difference was evident: Response rate was higher for the key than for the treadle.

The different measures of response rate showed the same effect of changes in FI value for both key and treadle responses: Response rate decreased as FI value increased. Although key rates decreased more than treadle rates, the key rates were greater than the treadle rates at all FI values. Increases in FI value resulted in an increase in FI pause for both key and treadle responses. While quarter-life remained relatively constant over different FI values for the key response, the quarter-life of the treadle response tended to increase as the FI value increased. These data showed many similarities in responding under the FI schedule for key and treadle responses. Although further study may show some differences between these two responses under the FI schedule as, for example, indicated by the quarter-life measure in this study, there do not seem to be major differences between treadle and key responses under conditions used here.

The treadle response shows many more long IRTs than the key response under a differential-reinforcement-of-low-rate schedule (Richardson \& Clark, 1976). As performance under the differential-reinforcement-oflow-rate schedules and measures of curvature under the FI schedules may be viewed as measures of "timing," it could have been predicted that measures of curvature would be greater for the treadle than for the key. In general, measures of curvature for treadle pressing were less than or equal to those for keypecking. However, three of four birds did have longer pauses at the 1,000 -sec FI value for treadle pressing, and the difference in quarter-life between the two responses seemed to systematically decrease as FI value increased. Perhaps very large FI values would show measures of curvature to be greater for treadle pressing than for keypecking.

\section{REFERENCES}

Bolles, R. C. Species-specific defense reactions and avoidance learning. Psychological Review, 1970, 77, 32-48.

Ferster, C. B., \& Skinner, B. F. Schedules of reinforcement. New York: Appleton-Century-Crofts, 1957.

Hemmes, N. S. Behavioral contrast in pigeons depends upon the operant. Journal of Comparative and Physiological Psychology, 1973, 85, 171-178.

KLein, M., \& Rilling, M. Effects of response-shock interval and shock intensity on free-operant avoidance responding in the pigeon. Journal of the Experimental Analysis of Behavior, 1972, 18, 295-303.

MCSwEENEY, F. K. Matching and contrast on several concurrent treadle-press schedules. Journal of the Experimental Analysis of Behavior, 1975, 23, 193-198.

Revusky, S., \& Garcia, J. Learned associations over long delays. In G. H. Bower (Ed.), The psychology of learning and motivation. New York: Academic Press, 1970.

Richardson, W. K., \& Clark, D. B. A comparison of the keypeck and treadle-press operants in the pigeon: Differentialreinforcement-of-low-rate schedule of reinforcement. Journal of the Experimental Analysis of Behavior, 1976, 26, 237-256.

Seligman, M. E. P. One of the generality of the laws of learning. Psychological Review, 1970, 77, 406-418.

Skinner, B. F. Operant behavior. In Contingencies of reinforcement: $A$ theoretical analysis. New York: Appleton-CenturyCrofts, 1969.

Westbrook, R. F. Failure to obtain positive contrast when pigeons press a bar. Journal of the Experimental Analysis of Behavior, 1973, 20, 499-510.

(Received for publication August 1, 1979.) 